\title{
Snakebite on the hand: lessons from two clinical cases illustrating difficulties of surgical indication
}

Gras S (1), Plantefève G (2), Baud F (1), Chippaux JP $(3,4)$

(1) Department of Medicine, Doctors Without Borders, Paris, France; (2) Polyvalent Reanimation Service, Victor Dupouy Hospital Center, Argenteuil, France; (3) Center for the Study and Research of Malaria Associated with Pregnancy and Childhood (Cerpage), Cotonou, Benin; (4) Institute of Research for Development (IRD - UMR 216“Mother and child facing tropical diseases"), Cotonou, Benin.

\begin{abstract}
Snakebite is a particularly important health problem in rural areas of tropical regions. A large number of victims survive with permanent physical sequelae due to local tissue necrosis. However, necrosis may be associated with compartment syndrome especially when the bite is on the hands or feet. Herein, we describe two cases reported at a rural district hospital in Central African Republic. The present study suggests that active multidisciplinary management may improve patient prognosis while evidencing how difficult it is to decide on surgical intervention.
\end{abstract}

Key words: snakebite, Africa, compartment syndrome, surgery.

\section{INTRODUCTION}

Since 2009, snakebites have been considered a neglected disease by the World Health Organization (WHO) (1). In sub-Saharan Africa, recent estimates suggest that about 1 million bites by venomous snake occurred, with 100,000 to 500,000 cases of envenomations and up to 30,000 deaths per year $(2,3)$. Such figures indicate that snakebites comprise a particularly important health problem in rural areas of tropical regions. Populations in these regions face high morbidity and mortality due to the poor access to health services. Although numerous victims survive, they have permanent physical sequelae due to local tissue necrosis which may result in psychological problems as well. The economic impact of their disability is also considerable.

Echis is one of the most frequent and dangerous snakes in West Africa and sub-Saharan countries. It is a small sand-colored snake that belongs to Viperidae family. Its venom contains mainly different proteins and enzymes such as metalloproteases that provokes edema, blisters, necrosis and hemorrhagic syndrome. The toxins may also induce compartment syndrome because of deep muscle edema. Echis bites require support of a multidisciplinary team and demand specific treatment (antivenom) - in order to stop the hemorrhagic process - and non-specific measures - in case of necessary surgeries, dressings, or skin grafts. Usually, such complications are timeconsuming and difficult to be treated. However, as suggested in the two cases reported in the present study, multidisciplinary approach can actually change the patient prognosis.

The two cases presented in a district rural hospital, in Paoua, Ouham-Pende Province, Central African Republic. The hospital was supported by Doctors Without Borders who provided equipments and human resources. This explains why antivenom and surgery were always 


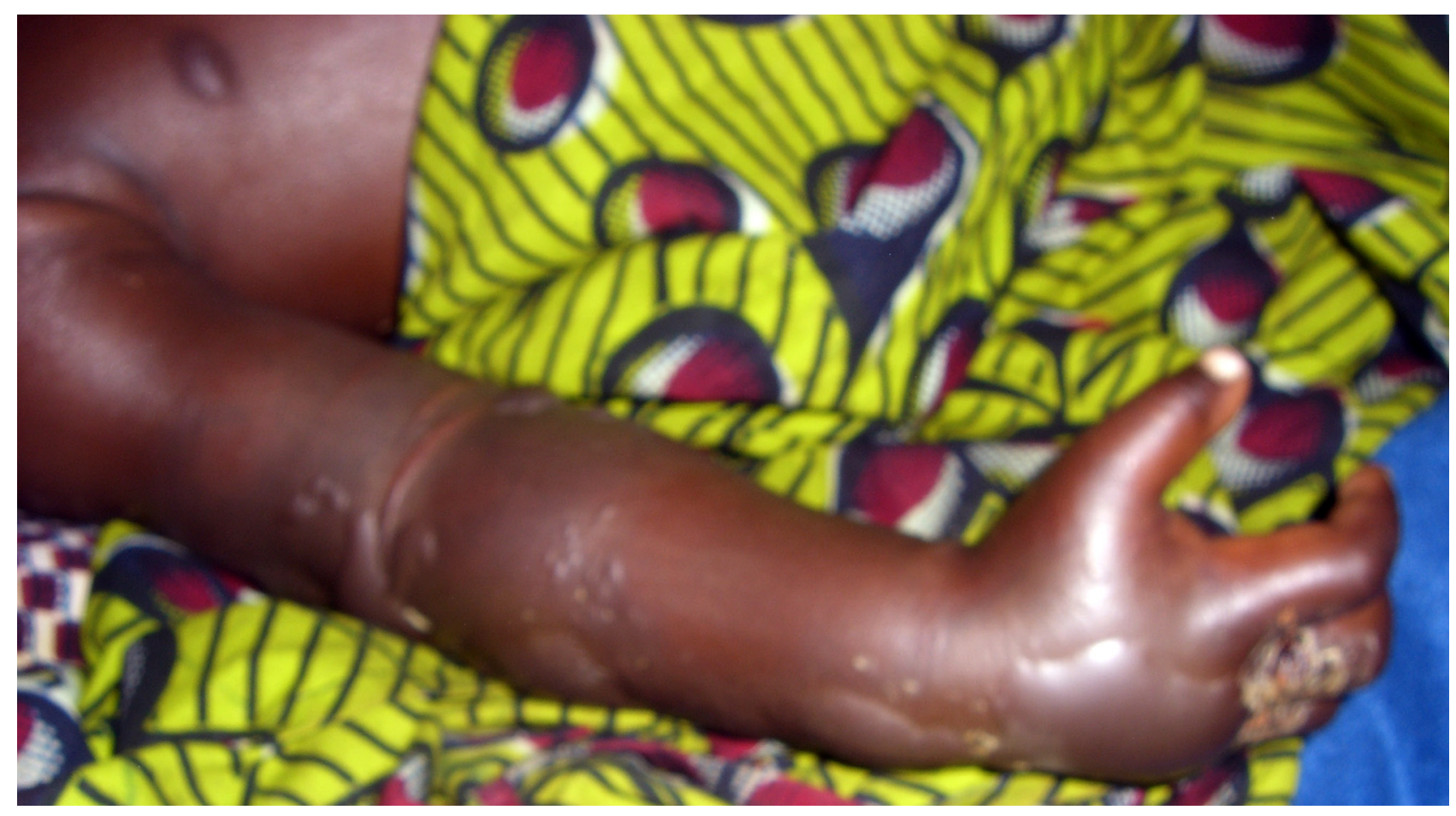

Figure 1. Initial examination showed that the right hand and forearm were swollen.

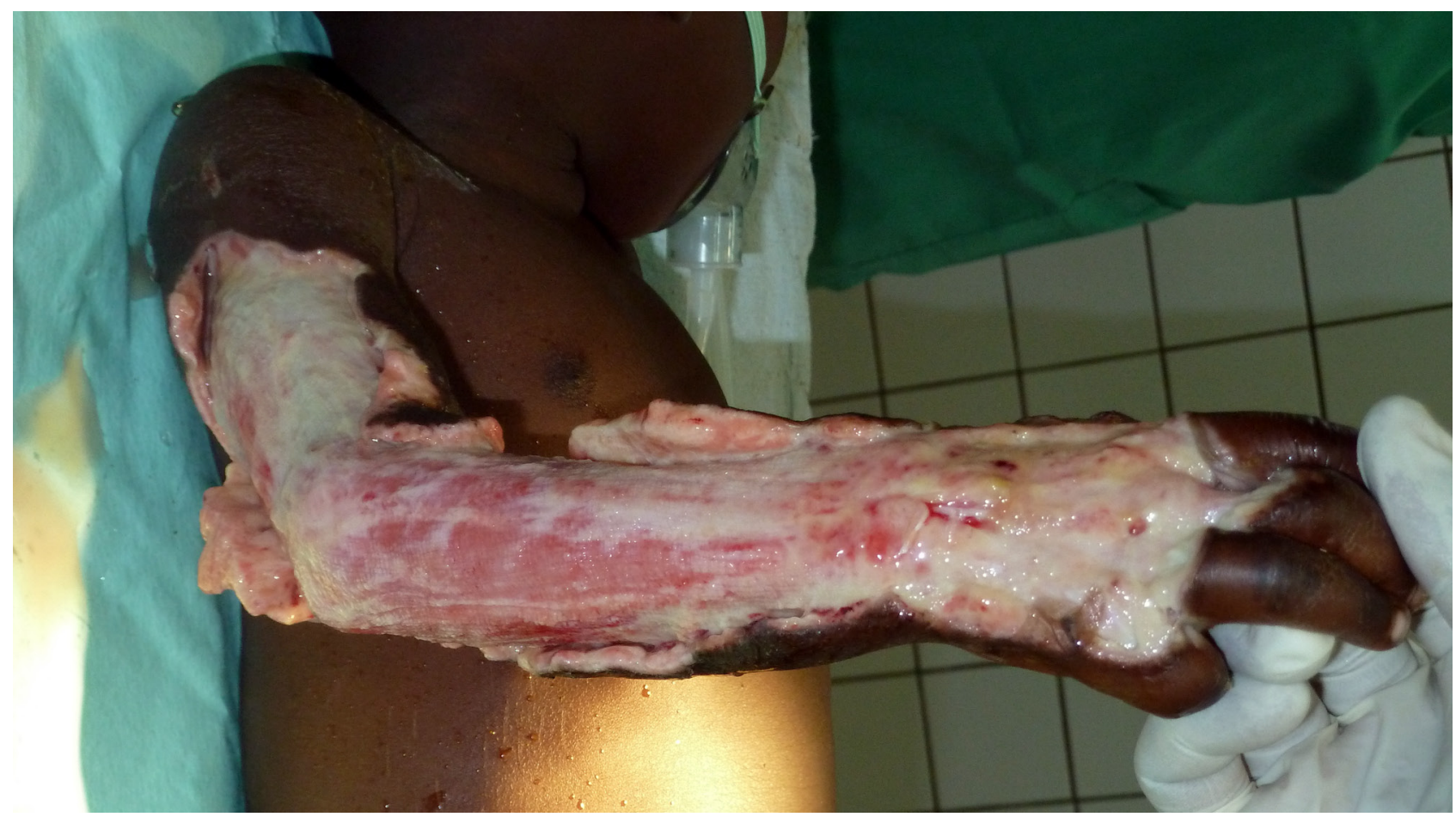

Figure 2. Initial perioperative observations. 


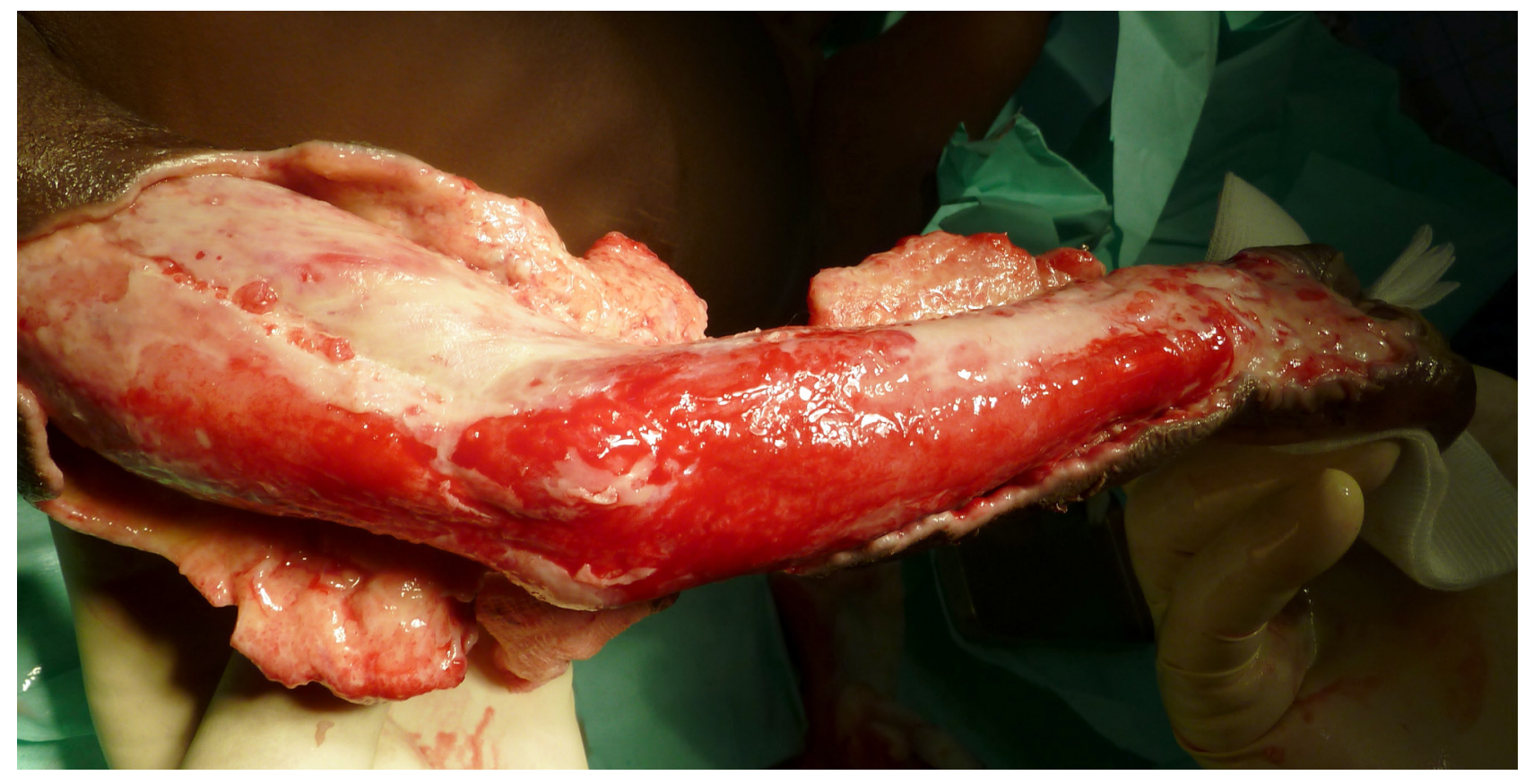

Figure 3. Wound cleaning.

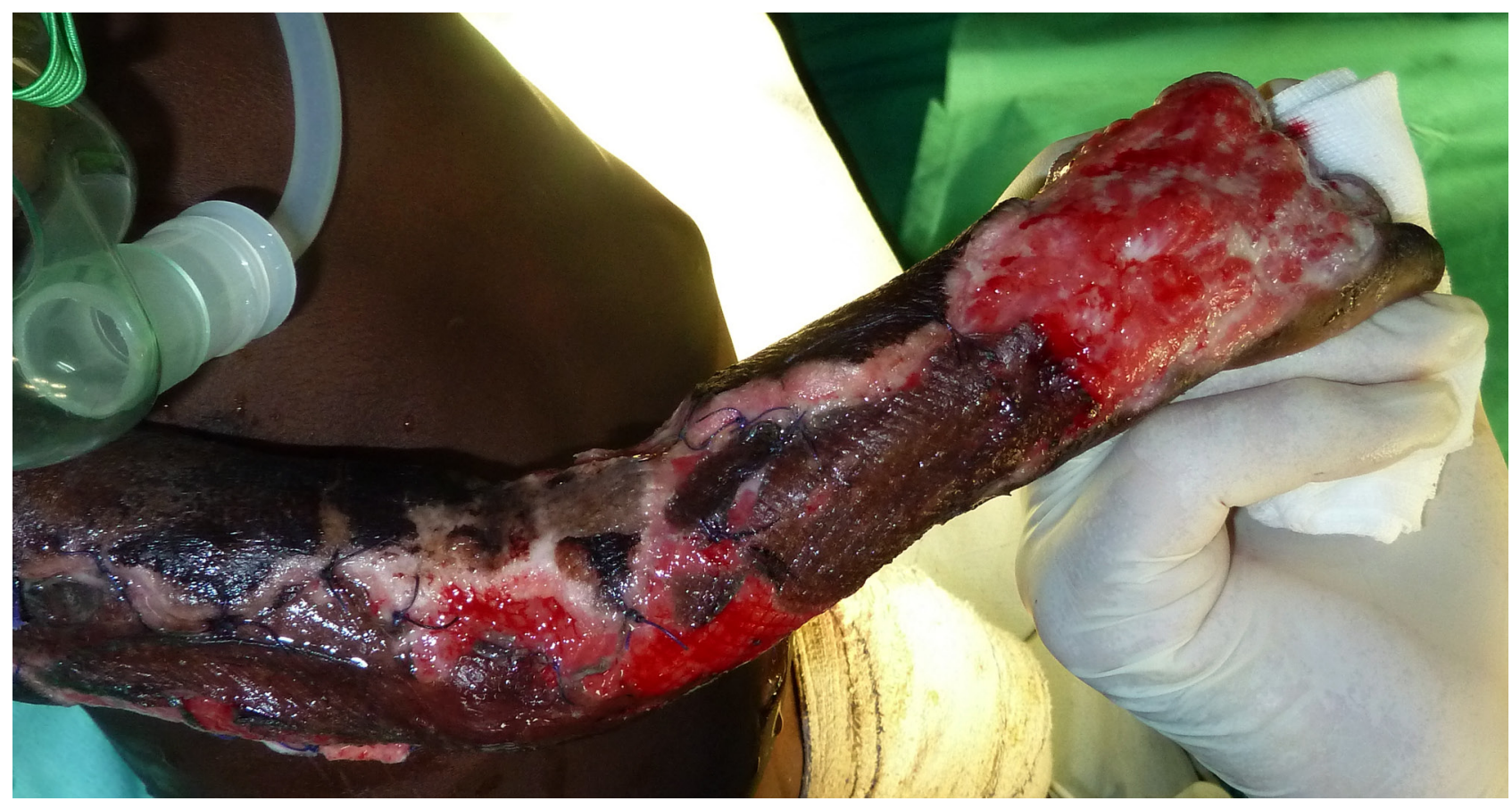

Figure 4. Skin graft. 


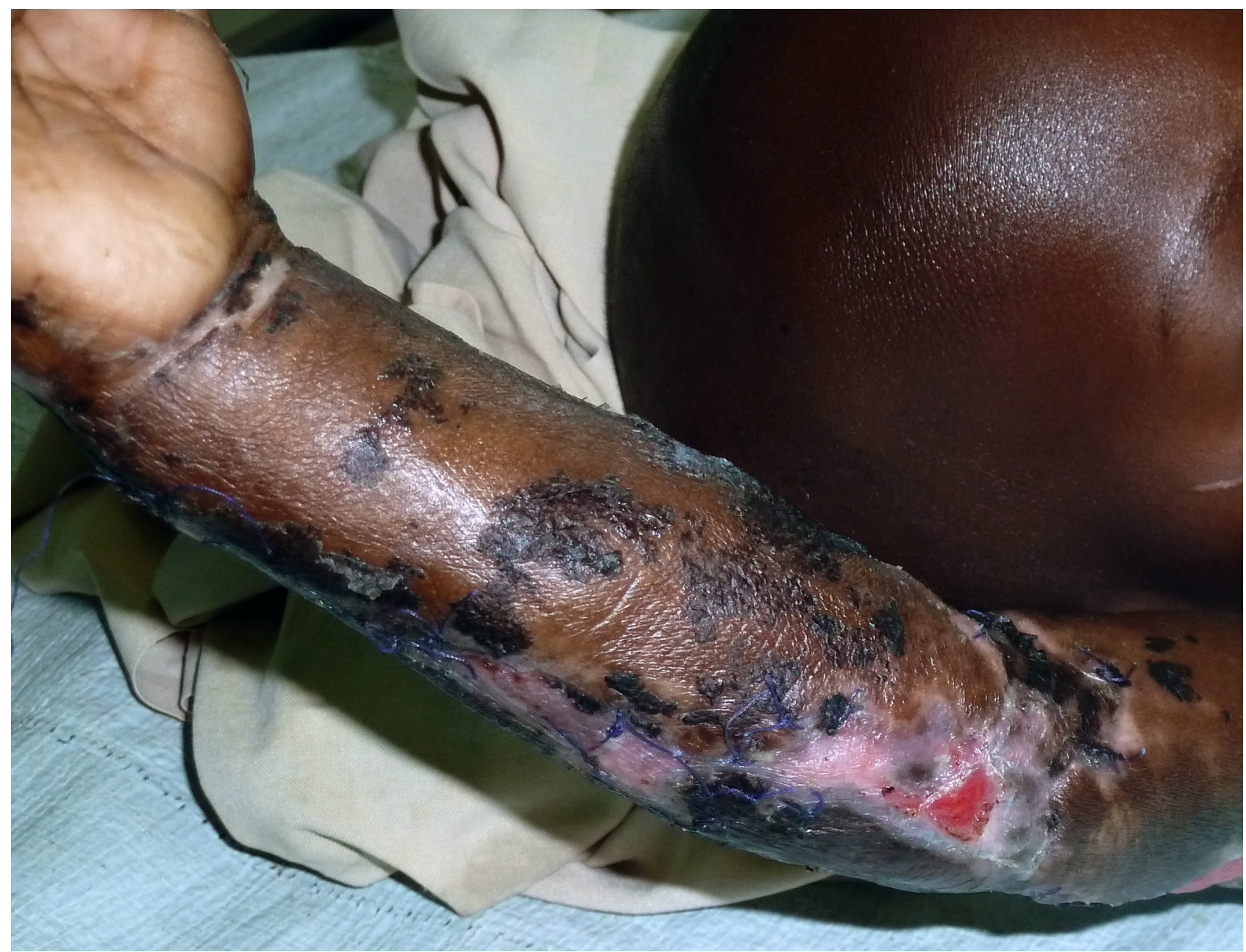

Figure 5. Final result.

available, in spite of their financial cost. In the hospital, a clinical study on snakebites was being carried out due to their high incidence in that area. From January 2009 to March 2011, 842 patients with snakebite history had been admitted, of which 825 were included in the study. We noticed that $25 \%$ of victims were bitten on their hand and $71 \%$ on the foot. The most frequent affected limbs in the region were similar in other parts of Africa and Asia (3-6). Out of the 825 patients, $68(10.6 \%)$ showed local complications, and 29 $(3.5 \%)$ of them required surgery.

\section{CASE REPORT 1}

A 18-month-old boy was bitten on his right hand early on the morning, when he was playing outside, on the floor, just in front of his parent's house. He presented in our hospital less than one hour after the bite. At initial clinical examination, there was no bleeding, no neurological abnormalities but the hand and the right forearm were swollen and very painful (Figure 1). Because of the extensive swelling, the child immediately received the first dose of antivenom (FAVAfrique $^{\oplus}$ ) in addition to the usual treatment including tetanus toxoid, tetanus vaccination, amoxicillin, acetaminophen, and ibuprofen.

Despite of the rapid first aid, the swelling was still increasing and the edema extended to the limb. He received a $2^{\text {nd }}$ dose of antivenom at day 1 , but without any notorious effect on the edema. The edema was evaluated and did not present any clinical bleeding or neurological signs. On Day 2, the swelling was still in progress and extended to the hemithorax. Therefore, he received a $3^{\text {rd }}$ dose of antivenom. Afterward, the swelling stopped, but the edema did not diminish.

Because of the extended edema with blisters and a possible associated compartment syndrome, the child underwent surgery at Day 4 for debridement and exploration. Perioperative 


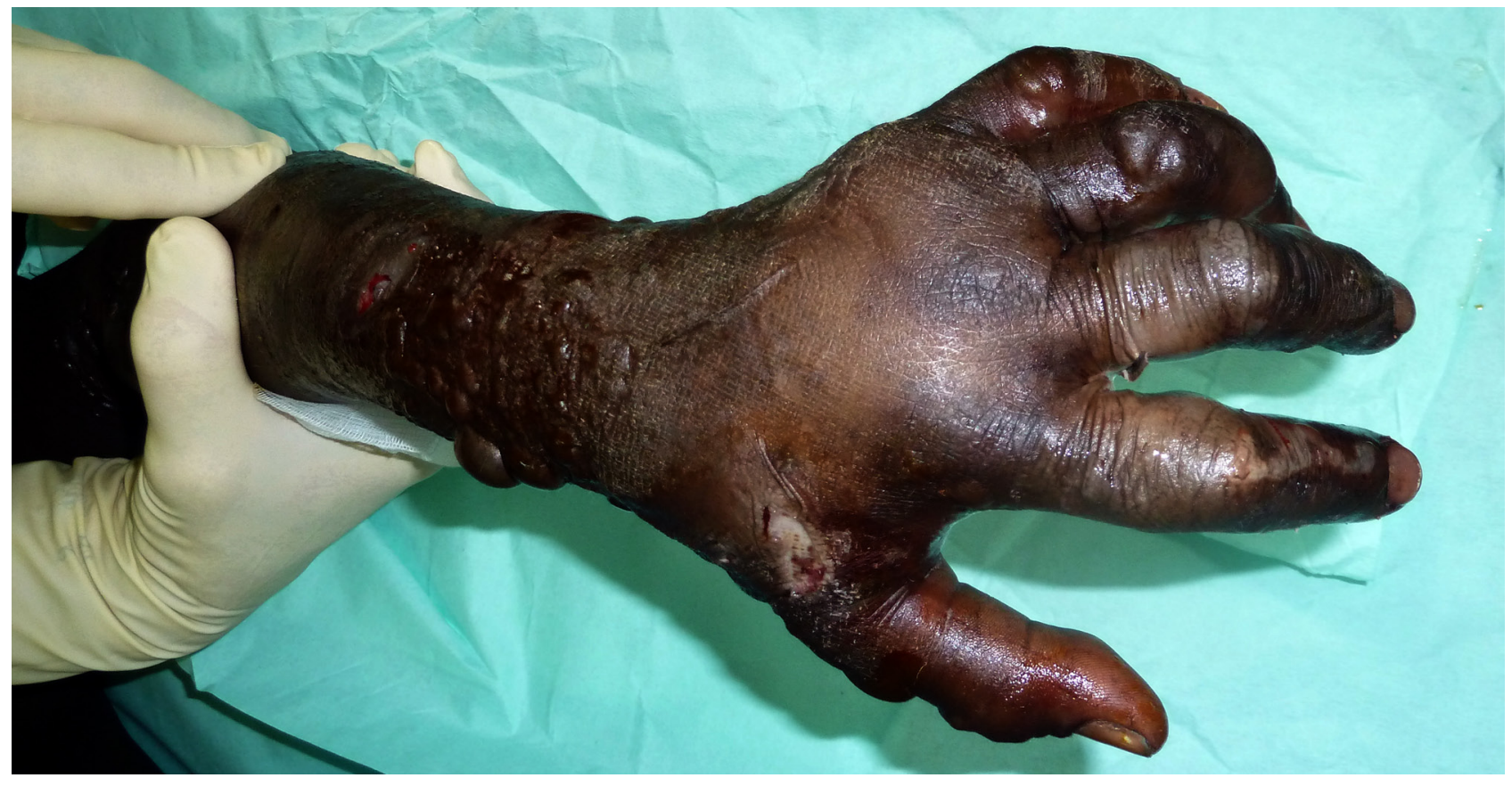

Figure 6. Initial aspect of the left hand.

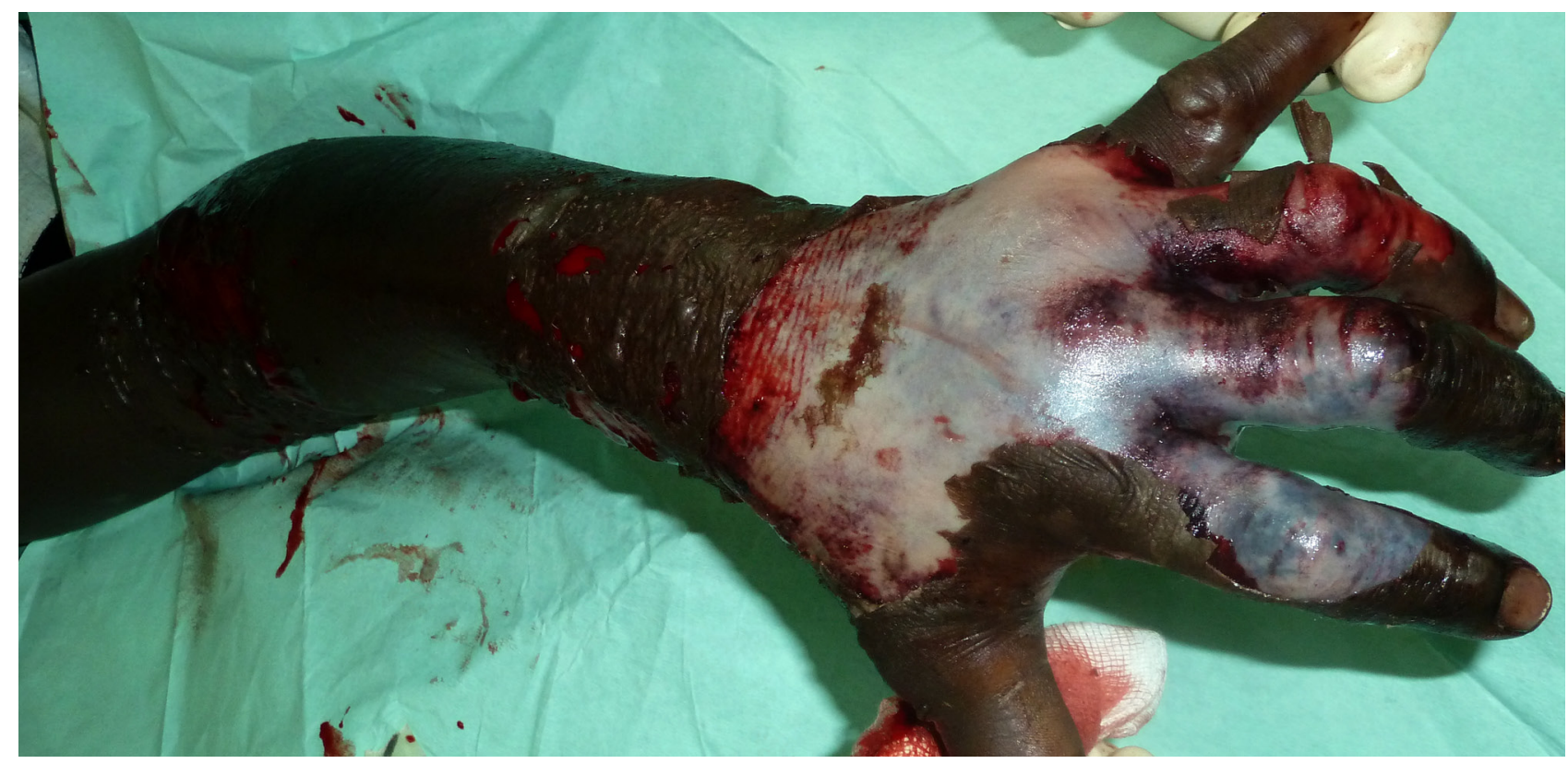

Figure 7. Initial aspect of the left hand, second image. 


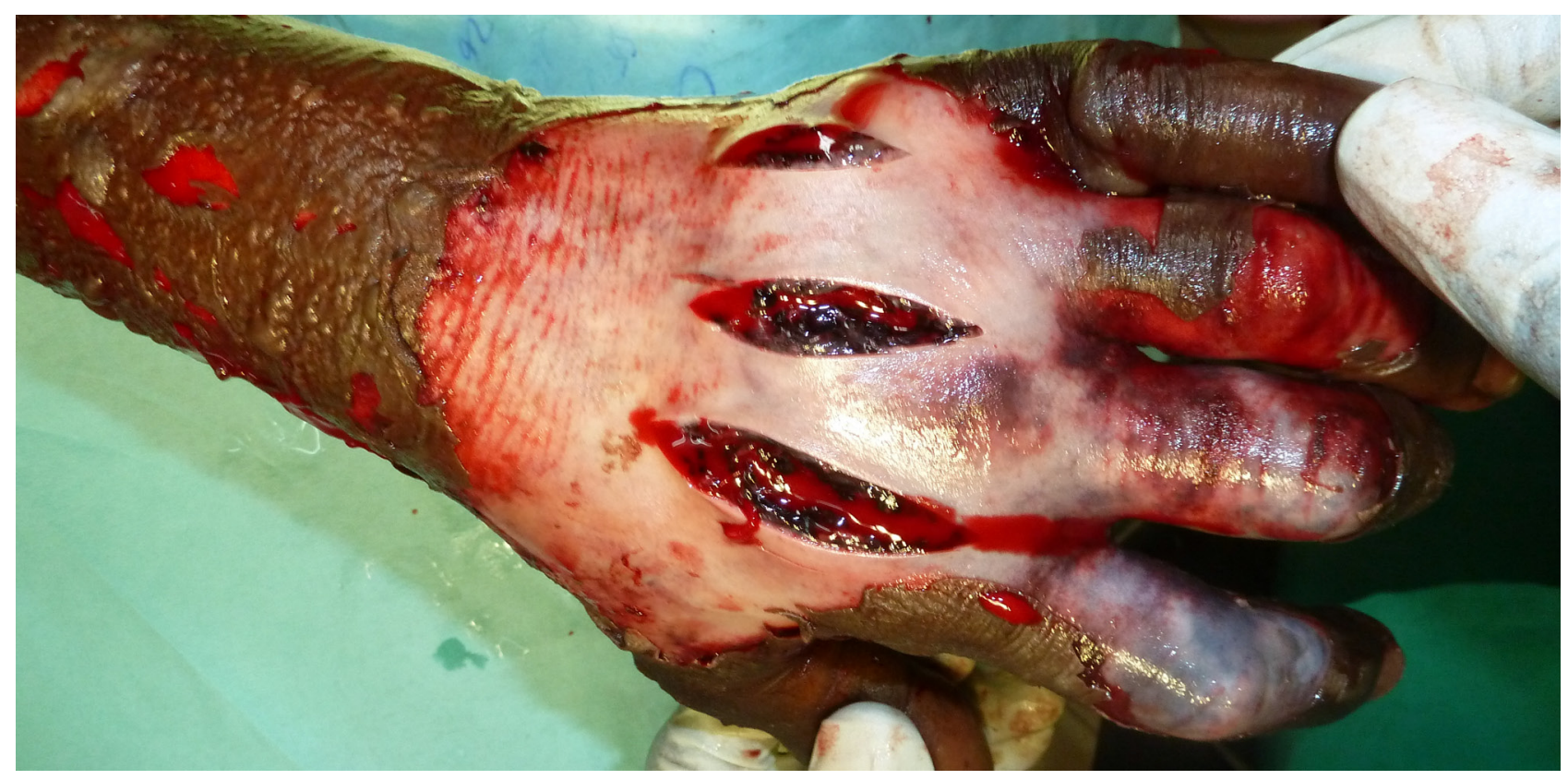

Figure 8. Fasciotomy.

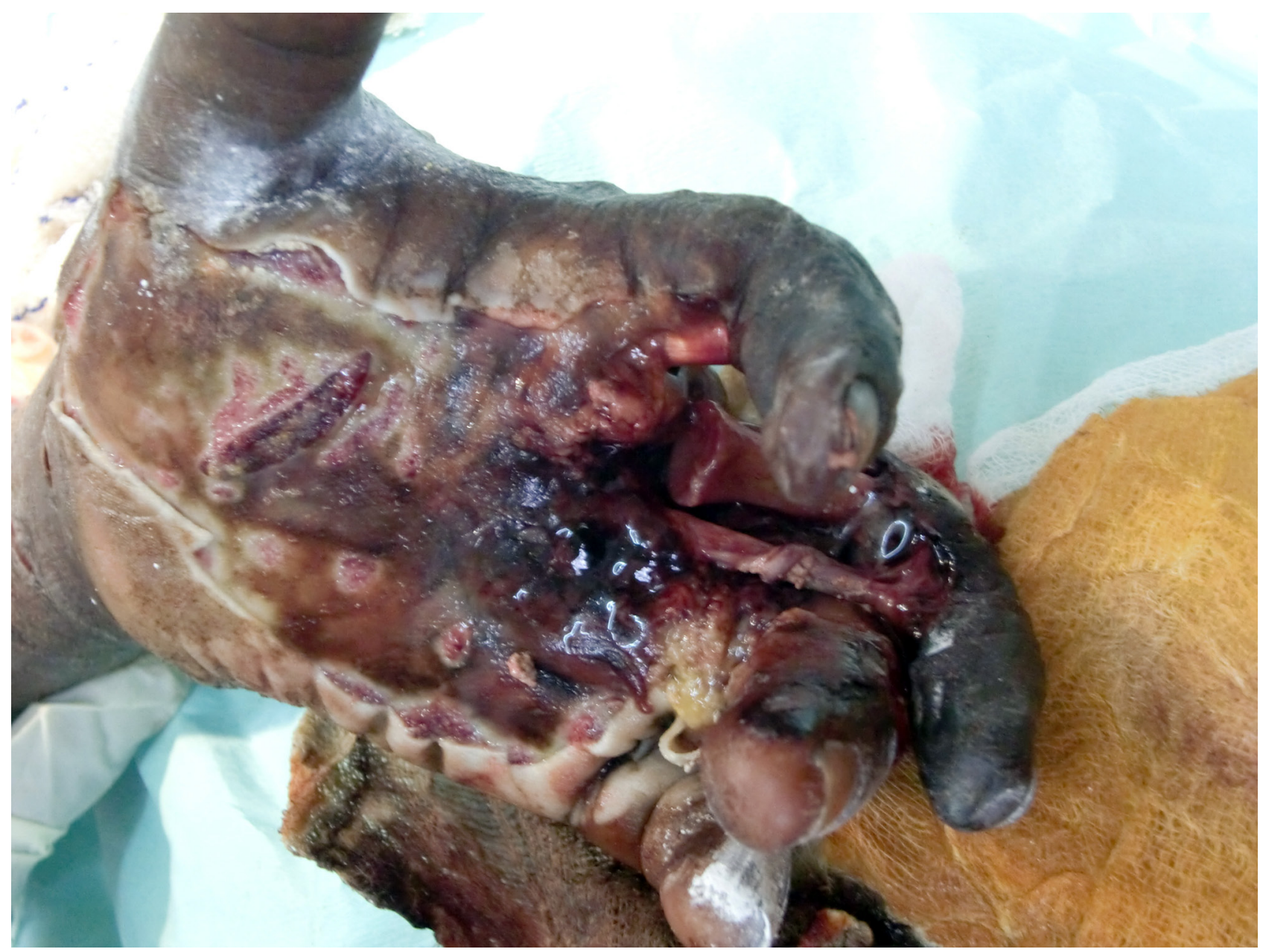

Figure 9. Necrosis aspect. 


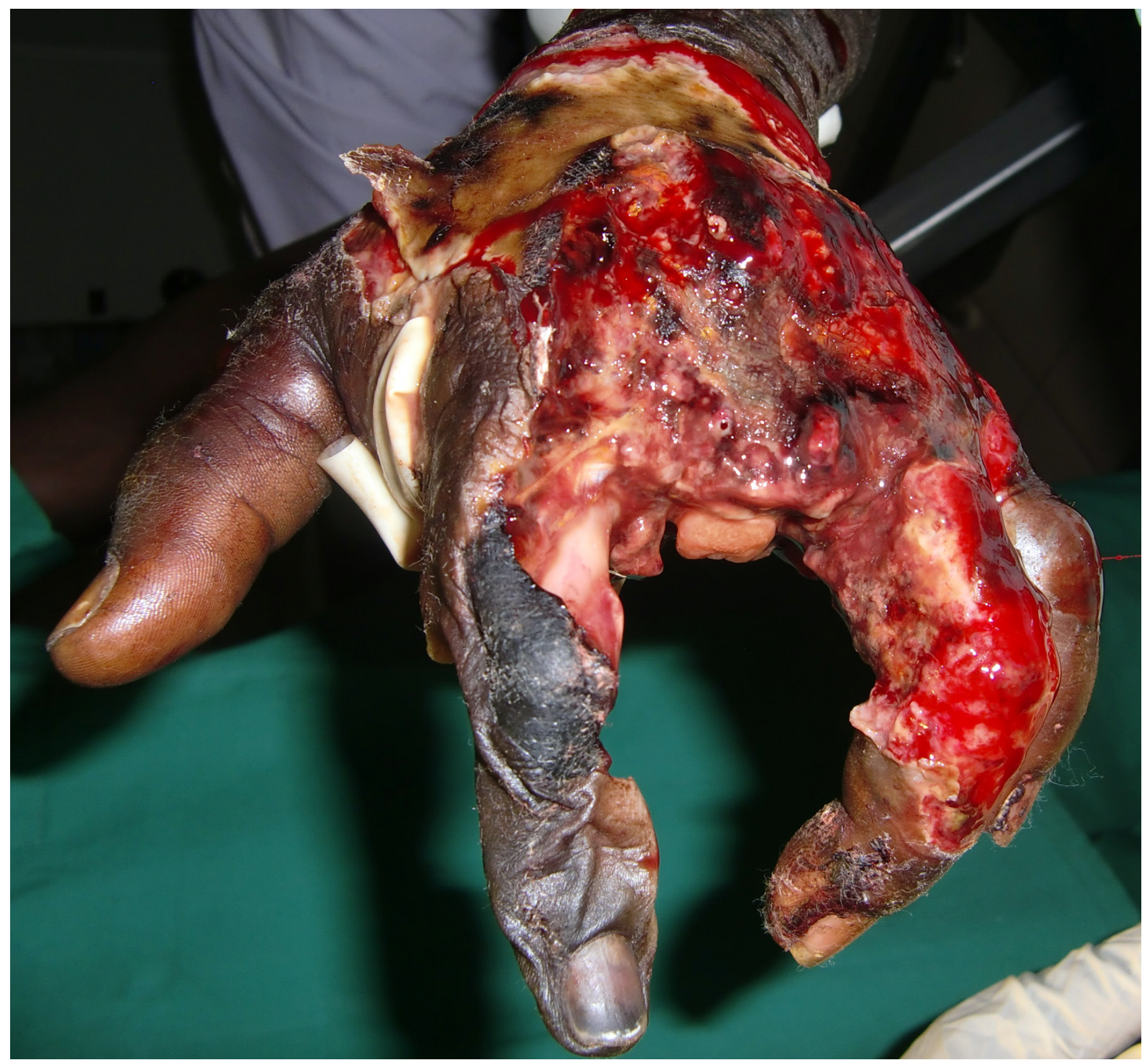

Figure 10. Finger amputation and necrosis.

observations showed massive subcutaneous necrosis reaching the entire arm, from fingers to the shoulder. But there was no evidence of compartment syndrome and muscular necrosis (Figure 2).

Because of the large wound due to skin debridement, the patient received a 7 -day prophylactic antibiotic therapy using amoxicillin and clavulanic acid. He went back to the operating room every 2 or 3 days for cleaning the wound and changing the dressing under general anesthesia (Figure 3). After 11 surgical interventions and 33 days at the hospital, the child's arm was finally skin grafted with a good result (Figure 4), which allowed doing the dressing without anesthesia, at the outpatient department. The final result of the procedures was aesthetically and functionally considered successful because there was no deficit except the $3^{\text {rd }}$ finger extensor (Figure 5).

\section{CASE REPORT 2}

A 13-year-old boy presented to our hospital because of snakebite on his left hand that had occurred six hours before. He was hunting bush rats, and when he put put his hand in a hole, he was bitten. On arrival he presented clinical hemorrhagic syndrome with gingival bleeding and an edema extending to his back and shoulder. Laboratory tests carried out included WBCT20 


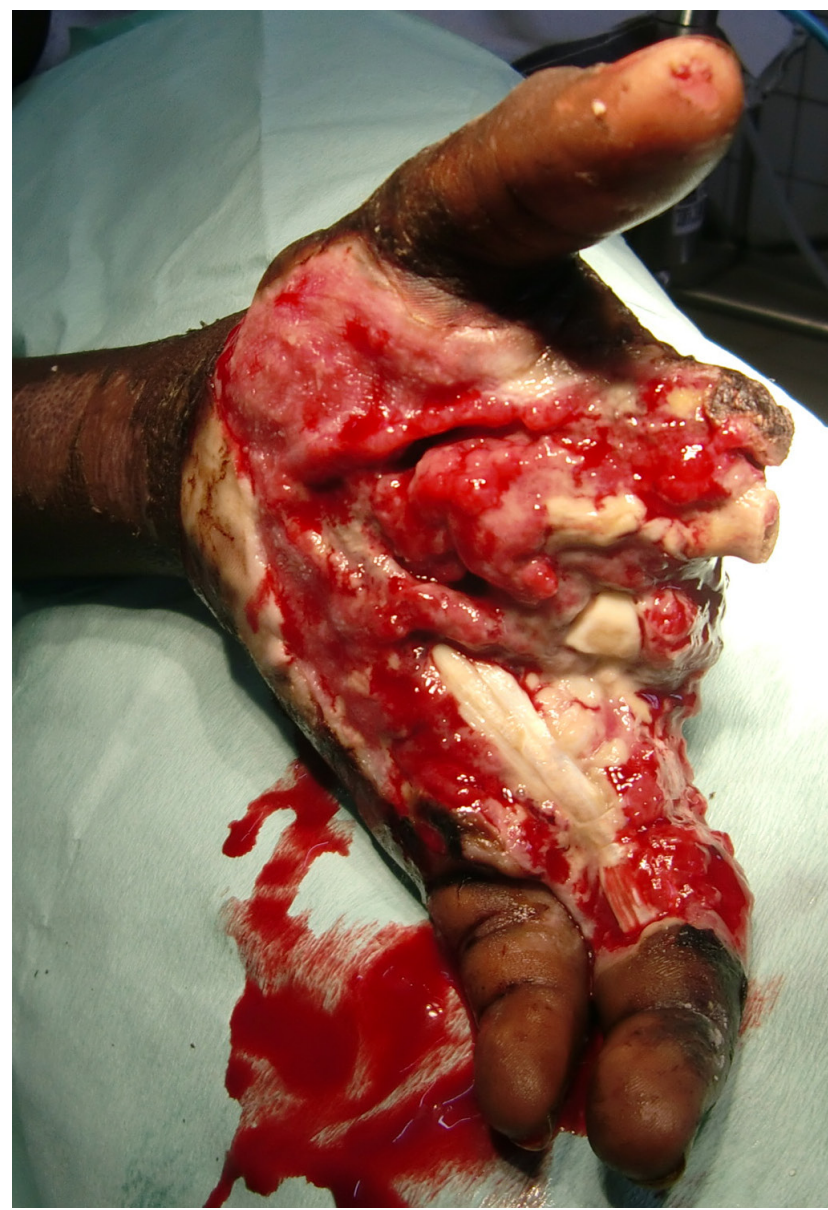

Figure 11. Finger amputation and necrosis, second picture.

(whole blood clotting test, 20 minutes) and the patient had incoagulable blood. Just after his admission, he received the first dose of antivenom $\left(\right.$ FAV-Afrique $\left.{ }^{\infty}\right)$ in association with the usual non-specific treatment (tetanus toxoid, tetanus vaccination, amoxicillin, acetaminophen, and ibuprofen).

Due to persistent swelling (the edema reached the thorax) he received a second dose of antivenom six hours after the first. Then, the edema stopped increasing and there was no more clinical bleeding. Although the edema stopped growing, the hand still had a worrying aspect. The skin was very hard; nails were white, without any evidence of blood circulation; and physical examination showed sensory and movement deficits (Figures 6 and 7). The patient underwent surgery on Day 1. Perioperative observations showed hand compartment syndrome and deep hematomas. Fasciotomy was performed and muscles below were black with almost no blood flow (Figure 8).
The patient went back to the operating room every 2 or 3 days in order to clean the wound and remove necrosis. The local evolution was unfavorable. Necrosis extended to the whole hand (Figure 9). Finger amputations were necessary (Figures 10, 11, 12).

After eight surgeries, his condition finally improved and the clean wound allowed a skin graft (Figure 13).

Unfortunately, the patient 'escaped' at Day 25 of hospitalization, before we could manage the skin graft. We did not have news from him. Unfortunately, the habit of being outside, in the bush, with such a wound and no sanitary supplies is of poor prognosis.

\section{DISCUSSION}

The two cases reported herein represent a relatively common situation in Africa and Asia (7-11). Children are particularly vulnerable when seeking food in rodent burrows or playing with what they find without understanding the hazard. It is often difficult to identify the species responsible for biting. Echis ocellatus is both the most common and the one for which the circumstances of the bite matched best. But we cannot exclude, particularly in the first case, a bite from Bitis arietans regarding the extension of the edema and the absence of bleeding.

Most of the literature is focused on snakebite mortality. However, many patients survive, and an elevated proportion of them suffer from local complications and sequelae. These may be due to the direct toxicological action of the venom associated or not with iatrogenic manipulations (12). Some enzymes induce tissue destruction, resulting in different levels of necrosis. Edema may compress blood vessels and prevent the vascularization of the extremities (compartment syndrome), which is exacerbated by vascular lesions caused by hemorragins, inappropriate treatments (tourniquet) or severe anemia caused by bleedings.

The outcome of the two reported cases may appear very similar (a necrosis leading to amputation), but the diagnosis and management are of course very different. A meta-analysis in 2011 reported an incidence of $5.5 \%$ of sequelae and $3 \%$ of amputations (8). In our own study, this rate is lower $(0.5 \%$ of amputation), probably because of our active support (as previously 


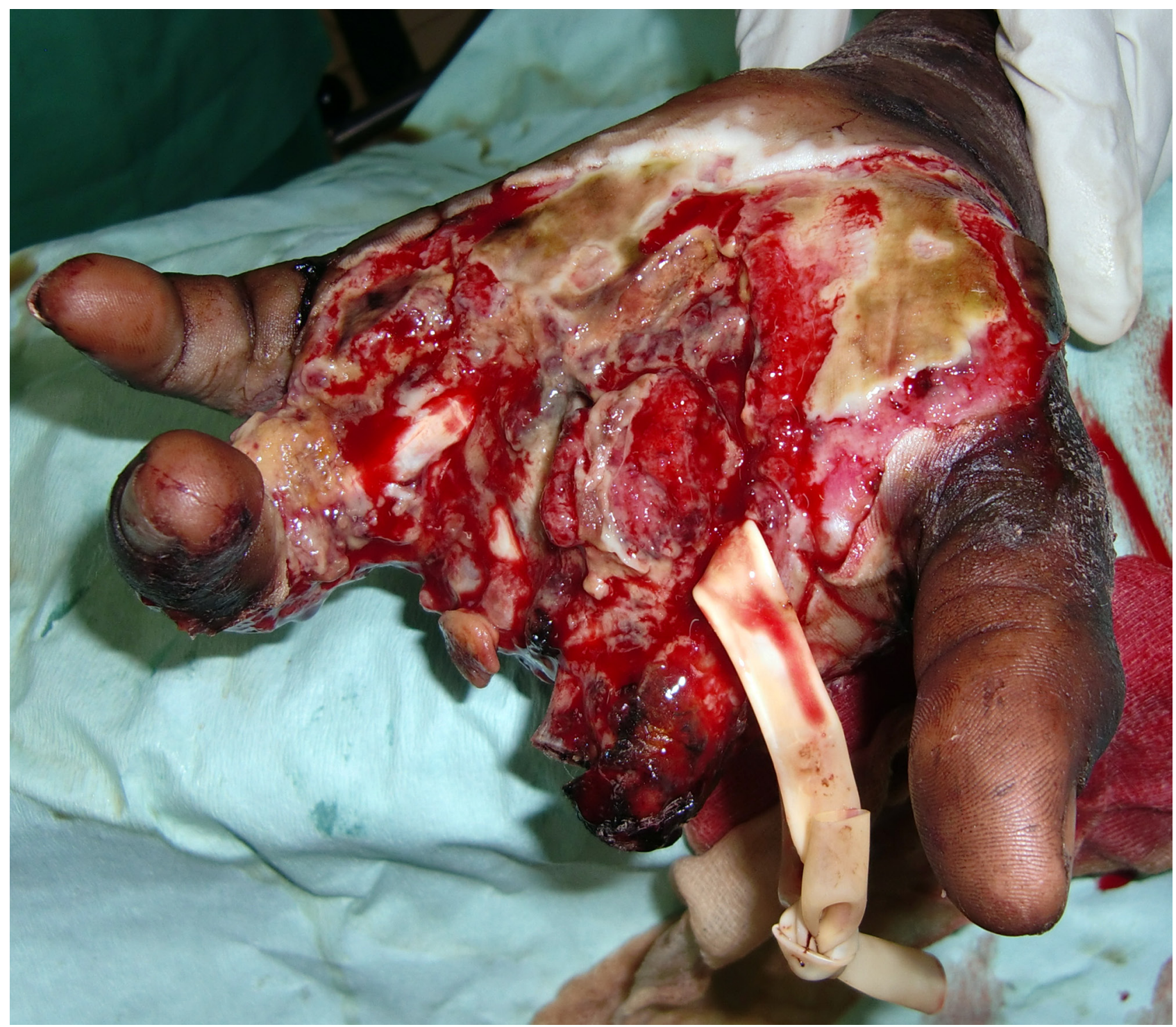

Figure 12. Finger amputation and necrosis, third picture.

mentioned). In rural tropics, decreasing and even avoiding physical sequelae, for an agricultural population is absolutely necessary, because physical strength means survival.

For a while, excision of necrotic tissue - and even amputation of the limb - was the heroic treatment of snakebite $(4,6,12)$. This strategy was justifiable when antivenoms lacked safety and were less effective, as well as resuscitation and surgery, than nowadays. The effectiveness of fasciotomy is not yet well demonstrated and more conservative treatments are now available $(4,10,11,13)$. On one hand, there is evidence that modern antivenoms both limit the spread of necrosis by inhibiting protease activity and reduce edema, leading to decreased risk of compartment syndrome $(14,15)$. On the other hand, symptomatic treatment (diuretics, mannitol) were also shown to be effective $(5,15)$.

As shown in the two case reports, worsening of a bite on the hand may develop rapidly. In the second case, despite the use of antivenom, compartment syndrome appeared within a few hours. And even an early surgery cannot avoid necrosis onset. This leads to a question: what are the indication and advantages of early fasciotomy in the management of compartment syndrome? Edema, especially if limited, is not enough to justify a fasciotomy. Ribeiro et al. (16) attempted to determine the risk factors for local complications. Bites on extremities, especially the hand, the size of the snake - which suggests a connection with the amount of venom (but also with the fang size because deep bites induce more 


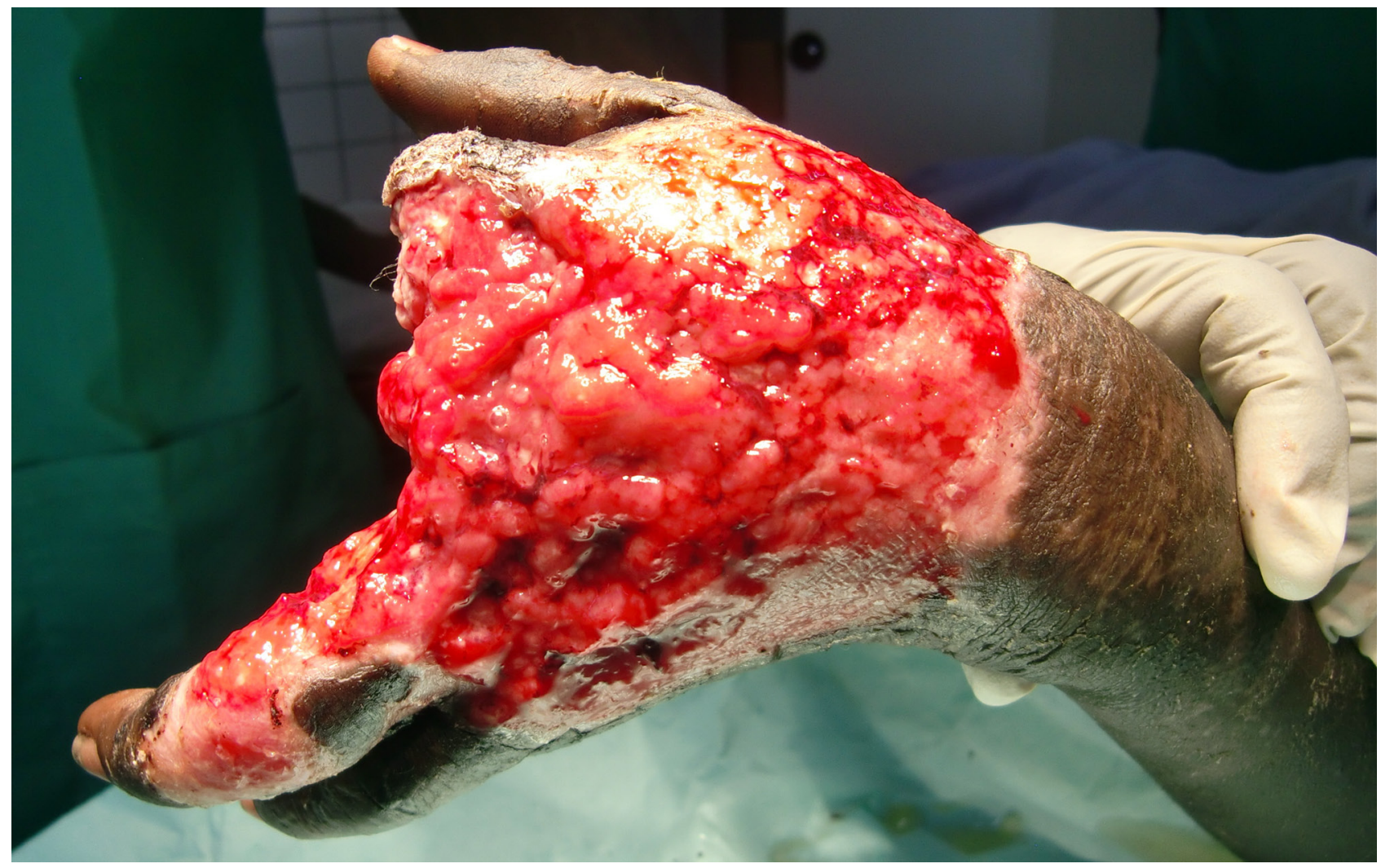

Figure 13. Clean aspect of the hand, after eight surgeries.

severe local complication) - and the severity of envenomation (associated with bleeding) may be considered risk factors (17). However, fortunately, most cases of envenomation are not complicated by compartment syndrome or sequelae $(7-9,12$, 13). In addition, infectious and hemorrhagic complications should be taken into consideration.

Some authors report a high level of hemorrhagic and infectious complications after early surgery (7). The indication of fasciotomy should not be based solely on clinical symptoms (edema and weakening or abolition of distal pulses). Measurements of intracompartmental pressure were described in 1975 (18), but are still rarely used in developing countries although they showed high interest (19-21). From experimental data, Garfin et al. (17) showed that the pressure measurement in deep compartments were more informative and relevant than the measurement of subcutaneous pressure. The latter varies little and within narrow limits, while measurement of deep intracompartmental pressure is likely to evaluate more efficiently the severity of ischemia. Several criteria have been defined, but it seems that the best estimate is given by the difference between the diastolic pressure and the intracompartmental pressure, which should remain less than $30 \mathrm{mmHg}(15,21)$. However, other clinical and biological parameters could be useful, such as oxymeters and ultrasonography.

To the best of our knowledge, conservative attitude (armed expectancy) appears to be the best approach for the management of local complications due to viper bite whether necrosis is due to tissue destruction by venom enzymes or distal ischemia-related compartmental syndrome. It is not easy to decide whether fasciotomy is indicated or not. Decision should also take into consideration local environment, equipment, and facilities. As shown in the two case reports, surgery, even in remote areas may be associated with good results, but it requires high investment from the medical team and the patient. It never comprises a one-shot surgery. However, if one can avoid iterative surgery, the benefit for patient could be very important. The main problem remains the surgical indication 
based on a multidisciplinary approach and not just on a clinical consideration.

\section{COPYRIGHT}

(c) CEVAP 2012

\section{SUBMISSION STATUS}

Received: September 19, 2012.

Accepted: October 23, 2012.

Abstract published online: October 29, 2012.

Full paper published online: November 30, 2012.

\section{CONFLICTS OF INTEREST}

The authors declare no conflicts of interest.

\section{FINANCIAL SOURCE}

The study was supported by Médecins Sans Frontières (French NGO "Doctors Without Borders").

\section{ETHICS COMMITTEE APPROVAL}

The present descriptive study based on medical records of Paoua Hospital was approved by CAR Ministry of Health.

\section{CORRESPONDENCE TO}

Séverine Gras, Département Médical, Médecins Sans Frontières, 8 rue Saint Sabin, 75011 Paris, France. Email: severine.gras@gmail.com.

\section{REFERENCES}

1. World Health Organization. Neglected tropical disease: snakebites [Internet]. WHO: Geneva; 2009 [cited 2009 Nov 23]. Available from: http://www.who. int/neglected_diseases/diseases/snakebites/en/index. html.

2. Kasturiratne A, Wickremasinghe AR, de Silva N, Gunawardena NK, Pathmeswaran A, Premaratna $\mathrm{R}$, et al. The global burden of snakebite: a literature analysis and modelling based on regional estimates of envenoming and deaths. PLoS medicine. 2008;5(11):e218. doi:10.1371/journal.pmed.0050218

3. Chippaux JP. Les serpents d'Afrique occidentale et centrale. Paris: IRD Éditions; 1999.

4. Cumpston KL. Is there a role for fasciotomy in Crotalinae envenomations in North America? Clin toxicol (Phila). 2011;49(5): 351-65.

5. Otero R, Gutierrez J, Beatriz Mesa M, Duque E, Rodriguez O, Luis Arango J, et al. Complications of Bothrops, Porthidium, and Bothriechis snakebites in Colombia. A clinical and epidemiological study of 39 cases attended in a university hospital. Toxicon. 2002;40(8):1107-14.

6. Huang TT, Blackwell SJ, Lewis SR. Hand deformities in patients with snakebite. Plastic and reconstructive surgery. 1978;62(1):32-6.
7. Chippaux JP. Snakebite in Africa: Current situation and urgent needs. In: Mackessy SP. Handbook of Venoms and Toxins of Reptiles. 2009. p. 453-73.

8. Chippaux JP. Estimate of the burden of snakebites in sub-Saharan Africa: a meta-analytic approach. Toxicon. 2011;57(4):586-99.

9. Abubakar SB, Habib AG, Mathew J. Amputation and disability following snakebite in Nigeria. Trop Doctor. 2010;40(2):114-6.

10. Laohawiriyakamol S, Sangkhathat S, Chiengkriwate P, Patrapinyokul S. Surgery in management of snake envenomation in children. World J Pediatr. 2011;7(4):361-4.

11. Chattopadhyay A, Patra RD, Shenoy V, Kumar V, Nagendhar Y. Surgical implications of snakebites. Indian J Pediatr. 2004;71(5):397-9.

12. Chippaux JP. Local complications of snake bites (author's transl). Med Trop. 1982;42(2):177-83.

13. Chippaux JP. Surgery should not be used as a first line treatment. J Venom Anim Toxins incl Trop Dis 2010;16(1):3-4.

14. Garfin SR, Castilonia RR, Mubarak SJ, Hargens AR, Akeson WH, Russell FE. The effect of antivenin on intramuscular pressure elevations induced by rattlesnake venom. Toxicon. 1985;23(4):677-80.

15. Gold BS, Barish RA, Dart RC, Silverman RP, Bochicchio GV. Resolution of compartment syndrome after rattlesnake envenomation utilizing non-invasive measures. J Emerg Med. 2003;24(3):285-8.

16. Ribeiro LA, Jorge MT, Lebrão ML. Prognostic factors for local necrosis in Bothrops jararaca (Brazilian pit viper) bites. Trans R Soc Trop Med Hyg. 2001;95(6):630-4.

17. Garfin SR, Castilonia RR, Mubarak SJ, Hargens AR, Russell FE, Akeson WH. Rattlesnake bites and surgical decompression: results using a laboratory model. Toxicon. 1984;22(2):177-82.

18. Whitesides TE, Haney TC, Morimoto K, Harada $\mathrm{H}$. Tissue pressure measurements as a determinant for the need of fasciotomy. Clin Orthop Relat Res. 1975;(113):43-51.

19. Mars M, Hadley GP, Aitchison JM. Direct intracompartmental pressure measurement in the management of snakebites in children. S Afr Med J. 1991;80(5):227-8.

20. Mars M, Hadley GP. Raised compartmental pressure in children: a basis for management. Injury. 1998;29(3):183-5.

21. Le Dantec P, Herve Y, Niang B, Chippaux JP, Bellefleur JP, Boulesteix G, Diatta B. Morsure par vipère Bitis arietans au Sénégal, intérêt de la mesure de pression intracompartimentale [Envenomation by the African puff adder (Bitis arietans): value of intracompartmental pressure measurement]. Med Trop. 2004;64(2):18791. 